\title{
MEDICAL ERRORS IN CLINICAL PRACTICE OF PHYSICIANS IN TERNOPIL REGION (UKRAINE)
}

Background. The professional occupation of a doctor quite often meets different imperfections, which have negative outcome for patients.

Objective. The study was aimed to investigate the expert characteristics of improper performance of the professional duties by medical staff on the example of a particular region of Ukraine.

Methods. In the study the archival materials (commission forensic medical examinations) held in Ternopil Regional Bureau of Forensic Medical Examination in 2007-2014 years were analysed. The research results are summarized and processed with the use of general statistical methods.

Results. It is defined that during this period 112 examinations concerning medical malpractice were implemented (9.05\% of all commission examinations).

Conclusions. Medical errors were combined, specifically during the diagnostics, treatment and in medical records. The majority of cases (82.1\%) of medical malpractice were caused by the objective reasons.

KEY WORDS: medical malpractice, medical errors, forensic medical examinations, dereliction of duty by medical personnel, negligence.

\section{Introduction}

The professional occupation of a doctor quite often meets different imperfections, which have negative outcome for patients. After the implementation of Criminal Code of Ukraine in 2001, especially Article 140 "Unjustifiable dereliction of duty by the medical or pharmaceutical practitioner", the number of criminal proceedings on the so-called "medical cases" significantly increased. This article became very important for forensic medical examination and for law in general, because of unintended events during medical care delivery and their legal correct qualification were foreseen in Ukrainian law for the first time. The experts of the World Health Organization consider that near 6-7 patients die every day in Ukraine as a result of medical errors. The Journal of Patient Safety released a new study in 2013 that estimated number of preventable medical errors above 440,000 annually [1].

Every case of inadequate medical care becomes an object of investigation which can't

Corresponding author: Valentyn Franchuk, Department of Pathological Anatomy with Forensic Medicine Course, I. Horbachevsky Ternopil State Medical University, 12 Ruska Street, Ternopil, Ukraine, 46001

Phone number: +380679835870

E-mail: franchukv@tdmu.edu.ua be implemented without the conclusion of the commission on forensic medical examination. This problem is not studied enough in contemporary Ukrainian forensic medicine. That is why the study of structure, occurrence and peculiarities of medical malpractice is the aim of the research.

\section{Material and Methods}

In the study archival materials (commission forensic medical examinations) handled in Ternopil Regional Bureau of Forensic Medical Examination (TRBFME) in 2007-2014 years were analysed. The research results are summarized and processed by general statistical methods.

\section{Results and Discussion}

During the studied period 112 examinations were conducted in TRBFME for "medical matters" (9.05\% of all commission examinations). Improper medical care was revealed in majority of the cases (92 (82.1\%)) when dereliction of duty by medical personnel occurred. The notion improper medical care or medical malpractice covers all unintended and wilful failures, omissions and defects of medical care delivery, treatment and intervention. Due to AngloSaxon system of law all failures in the doctors 
conduct are divided into two types: medical negligence and professional misconduct [2]. From the point of Ukrainian legislation all cases of unintentional medical intervention or lack of such can by classified into three main groups: medical maloccurrence, professional crimes of medical practitioners and medical errors. The term maloccurrence is the same both AngloSaxon and Slavonic law systems: inspite of good medical attention and care, an individual fails to respond properly or may suffer from adverse reactions of the drug [3]. The definition "professional crimes of medical staff" means inadequate medical care or medical intervention that foresees criminal liability of defendant. Gross breach of the standards of medical care occurs in those cases the severe consequences develop for a patient. This is similar to the term "criminal negligence" in Anglo-Saxon law system. Other cases of unsuccessful medical care are usually qualified in Ukrainian law as "medical errors" (similar to "civil negligence").

Totally, 19 cases $(20.6 \%)$ met unjustifiable medical care and were determined as crimes in medical sphere. Medical errors (civil negligence) were recognized by the forensic medical expert commissions in 73 cases ( $79.4 \%$ of all). The majority of such deviations were committed by hospital doctors and were performed during emergency medical care delivery [4]. The proportion of physicians facing an unintentional medical intervention or lack of such [5] ranged from $39.3 \%$ in anaesthesiology, $21.4 \%$ in inter- nal medicine, $18.7 \%$ in obstetrics and gynaecology, $17.8 \%$ in paediatrics, $14.3 \%$ in general surgery and $4.5 \%$ in family medicine, ophthalmology, neurosurgery, 3.6\% in neurology, $2.7 \%$ in oncology and $1.8 \%$ in psychiatry (Table 1 ).

The following mistakes were diagnosed by forensic medical examination: misjudgement of diagnostics ( $61.1 \%$ of cases), mistakes in medical records (46.4\%); mistakes during invasive procedures or medical treatment including medication errors (40.2\%), institutional defects $(27.7 \%)$, failures in the doctors conduct which impinge upon their professional relationships (deontological) were determined in $21.4 \%$ of cases. As a rule, forensic medical expert commissions established the presence of two different types of the mistakes (23.2\%) simultaneously, if for example misjudgement of clinical symptoms was combined with medication errors. The presence of 4 different types of mistakes were ascertained in $16.7 \%$ of "medical cases"; 3 defects (14.3\%); all kinds of defects $(3.6 \%)$. The following failures in the diagnostics were normally revealed: insufficient or incomplete general-clinical, laboratory and instrumental examinations; misjudgement of clinical symptoms; inadequacy of the clinical diagnosis; unskilful implementation of conventional special diagnostic methods and procedures. Mistakes during medical treatment including medication errors took place: the excess doses of medication, insufficient or excess amount of infusion, unjustified prescription of many the-

Table. 1. The prevalence of malpractice among medical practitioners

\begin{tabular}{|l|c|c|}
\hline \multicolumn{1}{|c|}{ Specialty of a physician } & $\begin{array}{c}\text { The number of cases in which } \\
\text { deficiencies of paramedics of certain } \\
\text { specialties were established (n=112) }\end{array}$ & $\begin{array}{c}\text { The percentage } \\
\text { on total amount } \\
\text { of research cases (\%) }\end{array}$ \\
\hline Anaesthesiologists & 44 & $39,3 \%$ \\
\hline Therapists & 24 & $21,4 \%$ \\
\hline Obstetricians & 21 & $18,7 \%$ \\
\hline Paediatricians & 20 & $17,8 \%$ \\
\hline Surgeons & 16 & $14,3 \%$ \\
\hline Traumatologists & 15 & $13,4 \%$ \\
\hline Infectiologists & 14 & $12,2 \%$ \\
\hline Emergency doctors & 10 & $8,9 \%$ \\
\hline Family doctors & 5 & $4,5 \%$ \\
\hline Ophthalmologists & 5 & $4,5 \%$ \\
\hline Neurosurgeons & 5 & $4,5 \%$ \\
\hline Radiologists and clinicians ultrasound & 5 & $4,5 \%$ \\
\hline Neurologists & 4 & $3,6 \%$ \\
\hline Oncologists & 3 & $2,7 \%$ \\
\hline Psychiatrists & 2 & $1,8 \%$ \\
\hline
\end{tabular}

Note: digital values exceed the total number of cases due to (in one case) deficiency assumptions on medical professionals of different specialties. 
rapeutic agents concurrently. Besides of these, the breach of care delivery standards, lack of monitoring data about a patient, omission of patient's condition, unforeseen complications etc. were detected too. The following institutional defects seemed more frequent: equipment malfunctions, absence of consultations; incorrect admission of a patient; inadequate monitoring of hospital administration about medical care. Numerous mistakes in medical records were found: the absence of hemodynamic parameters; superficial and incorrect description of objective state, lack of informed consent of a patient, inadequate clinical diagnosis, incomplete epicrisis etc. All deontological errors were commonly conducted with a poor qualification of medical staff, negative relationships between a patient and doctor, doctor and patient's relatives [6]. Approximately 30\% of all studied cases faced the breach of medical care standards.

Forensic medical examination confirmed the objective reasons for medical malpractice in almost $80 \%$ of cases. They were: the severity of patient's condition or the presence of comorbidity $(32.1 \%$ of cases); rapid duration of pathological process (21.4\%); difficulties in diagnostics or atypical manifestations of disease

\section{References}

1. James, John T. A New, Evidence-based Estimate of Patient Harms Associated with Hospital Care. Journal of Patient Safety 2013; 9(3): 122-128.

2. Shepherd R. Medical malpractice (in). Simpson's Forensic medicine. London. Arnold publisher; 2003: 15-26.

3. Narayan Reddy K.S. Professional negligence (malpraxis) (in). The Essentials of Forensic Medicine and Toxicology. Hyderabad. K. Suguna Devi publisher; 2006: 30-45.
(13.4\%). The subjective reasons (i.e., due to poor qualification of medical personnel) were detected in $9.8 \%$ of cases. All these cases were qualified as criminal negligence. Dereliction of duty by medical staff as a rule was accompanied by severe consequences for patients (fatality, grievous degree of severity, prolongation of illness, moderate degree of severity).

\section{Conclusions}

Dereliction of duty by medical personnel is confirmed more than $80 \%$ of "medical cases" in the conclusions of the commission forensic medical examinations.

The occurrence of unintentional medical intervention or lack of such in anaesthesiology, therapeutic, obstetrical/gynaecological, paediatric and surgical cases was more frequent. Unintended medical incidents were associated with and occurred during diagnostics, treatment, medical care, medication and in medical records. Considered inadequate medical care was usually insufficient and combined with breach of care standards.

The majority of medical errors happened due to different objective reasons. Criminal negligence was identified in about $20 \%$ of medical malpractice cases. 